\title{
Methods used and reasons for deliberate self harm: A cross-sectional study in acute care setting of Eastern Nepal
}

\author{
AK Yadav ${ }^{1}$, BK Rai ${ }^{1}$, R Bhandari ${ }^{1}$, PP Gupta ${ }^{1}$, DR Shakya ${ }^{2}$, M Moore ${ }^{3}$, SS Budhathoki ${ }^{4}$ \\ Department of General Practice \& Emergency Medicine ${ }^{1}$, Department of Psychiatry ${ }^{2}$ \\ Department of Rural Health Broken Hill University, Sydney, Australia ${ }^{3}$, School of Public Health \& \\ Community Medicine ${ }^{4}$, BPKIHS, Dharan, Nepal,
}

\begin{abstract}
Background: Deliberate self-harm (DSH) is a widespread yet often hidden problem in adolescents and young adults though most DSH can be classified as "non-suicidal self-cutting", some do go on to commit suicide. DSH present in acute settings of hospitals while limited information are found on reasons and methods for DSH in eastern Nepal. This study aimed at exploring the reasons and methods for deliberate self harm among patients presenting in acute setting of BPKIHS. Objective: To study the methods used and reasons for deliberate self harm in the patients presenting in emergency department and psychiatry outpatient clinics of BPKIHS. Method: Mix method (quantitative and qualitative) was used to conduct cross-sectional study using a pretested semi-structured questionnaire among 400 patients presenting in emergency department and out-patient clinic of Psychiatry department. In-depth interview was conducted among 12 respondents. Result: Four fifth of the patients, used poison as the method for DSH followed by hanging among less than a tenth of the patients. Majority (88\%) of the patients did not have any planning before committing act of DSH. Interpersonal conflict (48\%), financial reasons $(20 \%)$ and broken love affairs (16\%) are common events triggering DSH. Two-third of patients who presented with DSH were impulsive and almost two-fifth of them had depression. Conclusion: DSH was more common among the younger population. Advocacy to regulate the availability of pesticides for agricultural use may be needed to prevent the at risk population for accessing and using it for self harm. More community based studies to further explore the social aspects for the act of DSH and further researches is needed to design interventions to prevent the act of DSH at community level.
\end{abstract}

Keywords: Acute care, deliberate self harm, suicide, Nepal

\footnotetext{
Address for correspondence

Dr. Ajay Kumar Yadav, MD

Assistant Professor

Department of GP \& EM

B.P. Koirala Institute of Health Sciences, Dharan

Email: dr.ajaybpkins@gmail.com
} 


\section{Introduction}

Deliberate self harm (DSH) is a self-initiated behavior, with intended self-harm, resulting in injury or possibly death of the individual. ${ }^{1} \mathrm{DSH}$ is a premeditated act of self-inflicted injury with in which evidence exists that the person intended at some point to kill himself/ herself. ${ }^{2}$ Acts of deliberate self-harm (DSH) not only affect the people directly involved, but also have grave psychological and social impact on the family and community. ${ }^{3}$ Causes of suicide include depression, abuse (physical or sexual), loss of friends (including boy- or girlfriend), academic failure, social isolation, substance abuse, and others. Some youth who attempt or complete suicide have a history of self-cutting behavior. ${ }^{4}$

Suicide rates are up to almost 40 suicides per 100,000 people in Eastern Europe. In Asia, $30 \%$ of all suicides worldwide occur mainly in China, India, and Japan. In all regions, this poses a tragic loss of those in the most productive years of their life; in particular suicide is the main cause of death among young women in the Western Pacific Region and the second main cause of death among young men in the European Region. ${ }^{5}$

The rate of suicide and intentional self harm vary across various countries and communities, and are affected by various determinants pertaining to the individual and the environment. The methods used vary, depending upon the availability of means and also the severity of suicidal intent. Among the major causes of death in youth around the world, suicide ranked fifth or higher in all countries under study. ${ }^{4}$

Emergency department data for Alberta showed nearly 250 presentations for DSH per 100,000 populations in $2000 / 2001 .{ }^{6}$ According to a systematic review of published follow-up data from 90 observational and experimental studies, in the following year, around $2 \%$ will die by suicide and $16 \%$ will return to hospital for $\mathrm{DSH}^{7}$

In 2009, World Health Report stated that every year almost 1 million people commit suicide, every 40 second another family loses a loved one to suicide. ${ }^{8}$ It is one of the top 10 causes of death in all age groups and top three among 15-44 years worldwide ${ }^{9}$ and accounts for $1.8 \%$ of global burden of disease. ${ }^{10}$

The national police report data (November 22, 2008) shows an alarming rise in Nepal's suicide rate from 1,992 in 2004 to 2,789 suicides in 2007. Six hundred and fifty nine patients were reported during the first three months of 2008 alone maintaining the trend. A study conducted in BPKIHS shows that $22 \%$ of psychiatry emergency patients were brought to the hospital for deliberate self harm. Among them, nearly $65 \%$ were found to have been suffering from mental illness. ${ }^{11}$ However, reliable national data are not found on the socio demographic profile, the number of patients, the methods used, reasons or any 
other aspect of the patients of deliberate self harm especially the parasuicide patients. The estimates of the ratio of attempted suicides to completed suicides ranged from 8:1 to as high as $20: 1$ for the general population, varying markedly by age and gender. ${ }^{12}$

We found limited literature about methods and reasons for deliberate self harm presenting in acute care settings in our country. This study was conducted to explore methods used and reasons of deliberate self harm in the sociocultural settings of eastern Nepal.

\section{Methods}

A cross sectional study was carried out at the emergency room of Department of General Practice \& Emergency Medicine, and the outpatient clinic of the of Department of Psychiatry at B.P. Koirala Institute of Health Sciences (BPKIHS), Dharan, Nepal. The study used a mixed method (quantitative and qualitative). Sample size was calculated as 414 using a prevalence of $22 \%$ of deliberate self harm in a hospital based study from East Nepal and adding $10 \%$ sample size to adjust for non-responders. ${ }^{11}$ We studied 400 patients who agreed to participate in our study, providing a response rate of $96.6 \%$. All patients aged 16 years and above, presenting with a history of deliberate self harm attending hospital of BPKIHS was included in the study. All patients that presented with injuries inflicted by others and accidental injuries were excluded.

A pretested semi structured questionnaire was used to collect socio demographic profile, and the history related to the current hospital visit. The patients of deliberate self harm were consecutively selected from the emergency department in BPKIHS. The patients were interviewed in a one to one situation in all patients with the help of the questionnaire, particularly designed for the purpose once the acute medical/surgical emergency was over. This was done in emergency when possible. When this was not possible, the patients were followed up in the ward and interviewed prior to discharge. In all the patients at least one additional informant who knew about the patient and has witnessed the act were interviewed. The information given by the informant was matched with that of patient. The questionnaire included comprehensive list of etiological factor besides socio-demographic profile. Detailed history including past history and family history of deliberate self harm as well as questions regarding the reason were asked with the patients. Patients were then followed up in psychiatry outpatient department for any psychiatric diagnosis. The psychiatrist in our research team evaluated for psychiatric diagnosis, prominent personality traits and suicide intent. The patients of deliberate self harm were also classified into low, moderate 
and high suicidal intent groups according to the scores in the Beck suicide intent scale (BSIS). In depth interviews (IDIs) were conducted among 12 respondents out of which 10 were patients and 2 were the immediate family members. The interview schedule was made to identify the possible reasons leading the act of DSH.

The study was conducted after obtaining clearance from the Institutional Ethical Review Board (IERB) of B.P. Koirala Institute of Health Sciences (BPKIHS). Informed consent was taken from the patients as well as the caretakers before involving in the study.

\section{Results}

Two third of the patients (67\%) were from the age groups of 16-29 year. Male and female patients comprised of $50 \%$ each. Seventy six percent had completed at least primary education. Twenty-eight percent (28\%) of the total patients were low skilled workers and a predominant $70 \%$ had low socio-economic status. Remaining $30 \%$ were had a status as middle socioeconomic status. (Table 1)

Table 1: Socio demographic profile of the patients $(n=400)$

\begin{tabular}{|l|l|l|l|}
\hline \multicolumn{2}{|c|}{ Socio demographic characteristics } & Frequency & Percentage (\%) \\
\hline Gender & Female & 200 & 50 \\
\cline { 2 - 4 } & Male & 200 & 50 \\
\hline Marital status & Single & 144 & 36.0 \\
\cline { 2 - 4 } & Married & 256 & 64.0 \\
\hline \multirow{5}{*}{ Education } & Illiterate & 96 & 24.0 \\
\cline { 2 - 4 } & Primary & 192 & 48.0 \\
\cline { 2 - 4 } & Higher secondary & 104 & 26.0 \\
\cline { 2 - 4 } & University & 8 & 2.0 \\
\hline Home location & Urban & 208 & 52.0 \\
\cline { 2 - 4 } & Rural & 192 & 48.0 \\
\hline Occupation & House maker & 136 & 34.0 \\
\cline { 2 - 4 } & Student & 100 & 25.0 \\
\hline & Farmer & 64 & 10.0 \\
\cline { 2 - 4 } & Business & 40 & \\
\hline
\end{tabular}




\begin{tabular}{|l|l|l|l|}
\hline & Civil service & 12 & 3 \\
\cline { 2 - 4 } & Skilled worker & 48 & 12 \\
\hline
\end{tabular}

Table 2: Characteristics of the deliberate self harm act $(n=400)$

\begin{tabular}{|l|l|l|l|}
\hline \multicolumn{2}{|c|}{ Characteristics of the act } & Frequency & Percentage (\%) \\
\hline \multirow{4}{*}{ Methods } & Poison & 320 & 80 \\
\cline { 2 - 4 } & Hanging & 32 & 8 \\
\cline { 2 - 4 } & Burn & 20 & 5 \\
\cline { 2 - 4 } & Cut throat & 20 & 5 \\
\cline { 2 - 4 } & Cut blood vessel & 4 & 1 \\
\cline { 2 - 4 } & Drowning & 4 & 1 \\
\hline Mode & Unplanned & 352 & 88.0 \\
\cline { 2 - 4 } & Planned & 48 & 12.0 \\
\hline \multirow{4}{*}{ Suicidal intent } & Low & 192 & 48.0 \\
\cline { 2 - 4 } & Moderate & 136 & 34.0 \\
\cline { 2 - 4 } & High & 72 & 18.0 \\
\hline
\end{tabular}

Only $12 \%$ deliberate self harm were planned, $88 \%$ were unplanned and impulsive act. The three most commonly reported triggering events for deliberate self harm acts were interpersonal conflict (48\%), financialadversity/poverty/unemployment $(20 \%)$ and broken love affair (16\%). The least commonly reported motives were study related stress $(5 \%)$, health related problem $(4 \%)$, infertility $(3 \%)$, interpersonal conflict with other $(1 \%)$, extramarital relation of spouse $(1 \%)$, legal issue/action against near/dear (1\%) and death of near and dear $(1 \%)$.

Table 3: Triggering events for DSH $(n=400)$

\begin{tabular}{|l|l|l|}
\hline \multicolumn{1}{|c|}{ Triggering events } & \multicolumn{1}{c|}{ Frequency } & \multicolumn{1}{c|}{ Percentage } \\
\hline Interpersonal conflict & 192 & 48 \\
\hline Financial & 80 & 20 \\
\hline Broken love affairs & 64 & 16 \\
\hline
\end{tabular}




\begin{tabular}{|l|l|l|}
\hline Study related stress & 20 & 5 \\
\hline Health related problems & 16 & 4 \\
\hline Infertility & 12 & 3 \\
\hline Interpersonal conflict with others & 4 & 1 \\
\hline Extra marital affairs of spouse & 4 & 1 \\
\hline Legal action on near and dear & 4 & 1 \\
\hline Death of a close relative & 4 & 1 \\
\hline
\end{tabular}

Only $5 \%$ patients had a history of suicidal attempt in the past whereas $5 \%$ patients had family history of suicide as depicted in table 4.

Table 4: Characteristics of patients presenting with act of DSH

\begin{tabular}{|l|l|l|l|}
\hline \multicolumn{1}{|c|}{ Patient characteristics } & Categories & Frequency & Percentage \\
\hline \multirow{2}{*}{ History of past attempt } & No & 380 & 95.0 \\
\cline { 2 - 4 } & Yes & 20 & 5.0 \\
\hline \multirow{2}{*}{ Family history of suicide } & No & 380 & 95.0 \\
\cline { 2 - 4 } & Yes & 20 & 5.0 \\
\hline \multirow{2}{*}{ Physical illness } & No & 392 & 98.0 \\
\cline { 2 - 4 } & Yes & 8 & 2.0 \\
\hline \multirow{2}{*}{ Social cause } & No & 396 & 99.0 \\
\cline { 2 - 4 } & Yes & 4 & 1.0 \\
\hline \multirow{2}{*}{ Substance used } & No & 356 & 89.0 \\
\cline { 2 - 4 } & Yes & 44 & 11.0 \\
\hline
\end{tabular}

Out of the 20 patient with positive past history of suicidal attempts, 12 were females. The patients with positive past history of suicidal attempts had moderate to severe depressive episodes and all the previous attempts had been carried out within the duration of current depressive episode. Eight patients had the diagnosis of a "stress related and adjustment disorder" along with co morbid emotionally unstable personality disorder. The 12 patients with depressive episodes had 2-3 attempts of suicide within the past few months. The 
methods used for the attempt were similar in Depression was a common underlying the previous episodes as in the current condition comprising 36\%. Other psychiatric episode.

disorders that were present included: impulsive

There were 20 patients with family history of suicidal attempts. Among 20 patients, 16 patients were impulsive act and 4 were diagnosed patient of moderate to severe depression. act, stress related and adjustment disorders, alcohol use disorder, delirium and personality disorder. Psychiatric diagnosis and personality traits in DSH patients are given in table 5 .

Table 5: Psychiatric diagnosis \& personality traits of the patients $(n=400)$

\begin{tabular}{|l|l|l|l|}
\hline \multicolumn{2}{|c|}{ Psychiatric diagnosis and personality traits } & Frequency & Percentage \\
\hline Diagnosis & Impulsive & 228 & 57.0 \\
\cline { 2 - 4 } & Depression & 144 & 36.0 \\
\cline { 2 - 4 } & Adjustment & 16 & 4.0 \\
\cline { 2 - 4 } & Alcohol use disorder & 4 & 1.0 \\
\cline { 2 - 4 } & Delirium & 4 & 1.0 \\
\cline { 2 - 4 } & Personality disorder & 4 & 1.0 \\
\hline Personality trait & Well adjusted & 320 & 80.0 \\
\cline { 2 - 4 } & Cluster B & 16 & 16.0 \\
\cline { 2 - 4 } & Others & 64 & 4.0 \\
\hline
\end{tabular}

Assessment for personality trait showed that $\mathrm{B}$, and remaining $16 \%$ were maladjusted $80 \%$ were well adjusted, only $4 \%$ were cluster personality trait.

Table 6: Relationship of patient characteristics with planning of DSH act

\begin{tabular}{|l|l|l|l|l|l|}
\hline \multicolumn{2}{|c|}{ Patient characteristics } & \multicolumn{2}{|c|}{ Planned } & \multirow{2}{*}{ p-value } & \multirow{2}{*}{ Remarks } \\
\cline { 2 - 5 } & No & \multicolumn{1}{|c|}{ Yes } & & \\
\hline \multirow{2}{*}{ Age in years $(n=400)$} & $<30$ & 252 & 16 & \multirow{2}{*}{0.002} & \multirow{2}{*}{ Significant } \\
\cline { 2 - 5 } & $>30$ & 100 & 32 & & \\
\hline \multirow{3}{*}{ Family relation $(n=400)$} & Good & 208 & 12 & \multirow{2}{*}{0.026} & \multirow{2}{*}{ Significant } \\
\cline { 2 - 4 } & Not good & 144 & 36 & & \\
\hline
\end{tabular}




\begin{tabular}{|c|c|c|c|c|c|}
\hline \multirow{2}{*}{$\begin{array}{l}\text { History of past } \\
\text { attempt }(n=400)\end{array}$} & No & 348 & 32 & \multirow{2}{*}{$<0.001$} & \multirow{2}{*}{ Significant } \\
\hline & Yes & 4 & 16 & & \\
\hline \multirow{2}{*}{$\begin{array}{l}\text { Psychiatry diagnosis } \\
(n=160)\end{array}$} & Depression $(n=144)$ & 112 & 32 & 0.018 & Significant \\
\hline & Adjustment ( $\mathrm{n}=16)$ & 8 & 8 & 0.017 & Significant \\
\hline \multirow{3}{*}{ Personality trait $(n=400)$} & Well adjusted & 76 & 4 & \multirow{3}{*}{$<0.000$} & \multirow{3}{*}{ Significant } \\
\hline & Cluster B & 2 & 2 & & \\
\hline & others & 10 & 6 & & \\
\hline \multirow{3}{*}{ Suicidal intent $(n=400)$} & Low & 47 & 1 & \multirow{3}{*}{0.008} & \multirow{3}{*}{ Significant } \\
\hline & Moderate & 28 & 6 & & \\
\hline & High & 13 & 5 & & \\
\hline
\end{tabular}

Qualitative findings on reasons for will she realize that I was right". (25 years, deliberate self harm male).

In depth interview was conducted among 12 "I feel defeated. I have no reason to live. I feel respondents out of which 10 were the patients people are mocking at my situation. Only and 2 were the immediate family members. someone who has gone through what I have The patients reported helplessness, gone through will understand", said a 22 year desperation to prove one-self and wanting to old female who reported 'broken love affair' as end the situation as their reasons for act. The a reason for act of DSH. A 32 year old man immediate family members reported that, they did not think that this would happen and did not with financial problem sighed, "I am surprised. I have a slightest hint that the problem was this difficult to handle.

still don't know why I did this." A patient had lost her eldest sister due to complete suicide by drowning during the period of an illness. She had A 23 year old female patient expressed it was been deeply hurt by the act and within 2 weeks not possible for her to live with her thoughts anymore. She sighed, "...I wanted to end it once and for all...". Another patient who expressed 'interpersonal conflict' as a reason for act of DSH bluntly said, "She has to pay for my death to the society. Only when I am gone of that event, the current depressive episode of the patient had started. This 19 year old female also had planned and chosen the same method for the attempt. She said with disappointment, "I have no reason to live, my sister whom I love so much is gone." 
Immediate family member of a patient with 'study related stress' exclaimed, "Even in my extreme thoughts, it did not come to me that she would do this. We thought she is getting serious with her studies. We had a pleasant dinner together, just the night before. "

\section{Discussion}

More than a third (67\%) of the patients were within the age range of $16-29$ years close to the finding in another study from Nepal which showed $76 \%$ incidence in the same age group. $^{3}$ Studies of deliberate self harm in western Nepal, and another have also shown a high rate of attempted suicide in young people, especially those in the age range of 15-24 years, with the maximum number of patients falling within these age ranges. ${ }^{13,14}$

In this study there were male to female ratio is 1:1 while Shakya, reported a female preponderance with a ratio of $2: 5 .{ }^{13}$ The patients had been consecutively drawn from the emergency and fully evaluated for co morbid psychiatric conditions in psychiatric OPD and various wards once emergency was managed. Suicide has been reported in different studies carried out in this hospital. ${ }^{11,14,15}$

Regarding other socio-demographic variables of the patients of deliberate self harm, in the marital status, majority (64\%) of total patients were married and 36\% were unmarried. The number of married individuals in this study was nearly two times higher than the unmarried population. Shakya, however reports that there was no difference between married or unmarried individual committing deliberate self harm. ${ }^{13}$

In the study, $52 \%$ were from urban and $48 \%$ belonged to rural set up in contrast to the study by Neulinger, who reported that the total suicide rate in rural Australia was approximately $50 \%$ greater than the urban rate. However, our study which is hospital based. ${ }^{16}$ The difference in urban and rural composition of our study population could have been influenced by the composition of the general population of the districts of Jhapa, Morang and Sunsari which also have similar urban rural population distribution.

Our study group had more patients from the districts of Jhapa, Morang and Sunsari which might be due to the proximity of these districts to the hospital and easy availability of means of transportation. A large number of researches have considered the factors which influence the choice of method of attempting suicide and the extent to which access to specific methods of suicide. ${ }^{14}$

In current study, majority of the patients had chosen self poisoning (80\%) as the method for deliberate self harm, followed by hanging (8\%). This was followed by methods likes cut throat $(5 \%)$, burn $(5 \%)$, cut blood vessel $(1 \%)$ and drowning (1\%). These data are consistent with various international and national studies. The 
hospital based study by Shakya, showed that out of 71 self harm patients, $53.5 \%$ used poison. Another study from BPKIHS also showed poisoning to be the most common mode, Shakya. ${ }^{11,13}$ The commonest poison used was organophosphorus compound. This might be linked to easy availability and lack of regulation regarding sale of such compounds. Similarly, as majority of the subjects were from the Terai districts where pesticides are more easily available due to the agricultural background, the number of patients consuming organophosphorus is also high. In Nepal, there are inadequate laws and provisions which monitor and restrict the sales of such poisons and drugs and thus, anyone can have an indiscriminate access to such substances. This might partly explain the current findings. Both availability and socio-cultural acceptability determine the choice of the method of suicide. $^{16}$

Males usually choose more violent methods of deliberate self harm compared to females as shown by Roy and another study by Subba. 3, 17 In our study also, violent means like hanging, cut throat, cut blood vessel and drowning most frequently used by males.

In a study by Vajda, 79\% of the patients of attempted suicide had acted in the context of a dispute with a family member or a partner, followed by break up of relationship. ${ }^{18}$ The study by Pradhan, found family conflict, marital conflict, breakup of love affair and failure in academic performances to be the reasons precipitating the act in $82.4 \%$ of the patients. ${ }^{18 \text {, }}$ ${ }^{19}$ While the percentages differ, the reasons found are similar in this study.

In the study related to repeated suicide attempts by Vajda, 39\% of sample had a past history of attempted suicide on more than one occasion. There were no statistically significant differences between the proportion of males and females who had attempted suicide prior to or within 12 months of index suicide attempt. $^{18}$

However, in our study, past history of suicidal attempt was seen in $5 \%$ of the patients which is similar to the study by Pradhan, which found a positive past history in $5.9 \%$ of the patients. ${ }^{18}$ The presence of previous attempts is a serious and alarming signal for the close ones or family members to become alert enough to watch these individuals and anticipate such an attempt again in future. A family history of suicide or a psychiatric disorder, Mann also contributes to the risk of suicide and attempted suicide. In our study, however, family history of attempted suicide is present in only $5 \% .^{20}$ Vajda found depressive disorders among 46\% of the patients while our study showed a slightly lower (36\%) proportion having depressive disorders. However adjustment disorders (4\%), alcohol abuse (1\%) were found to be present in very low proportion compared to the study by Vadja as alcohol abuse/ dependence (35\%), and adjustment disorders 
(24\%). Co morbidity was present in $38 \%$ with personality and substance use disorders co occurring with depression. A study in Kathmandu shows the association with psychiatric morbidities in $45.1 \%$ of patients. A study by Shakya DR, from BPKIHS in psychiatry emergency patient had reported $65 \%$ patients with psychiatric illness among suicide attempters. ${ }^{11,18,19}$

In our study substance used disorder were found in $11 \%$ of patients. A study by Shakya, found alcohol use disorder was common in our set up. Psychiatric disorders are common among substance users which predispose to suicidal behavior. ${ }^{21}$

Almost half of patients in our study had low suicidal intent (48\%). Findings from IDIs highlight that the reasons for the act varies from persons to person. This study used qualitative methods to add indepth understanding of the quantitative findings. A separate qualitative study on reasons of DSH may provide more evidence and understanding on DSH for further discussion.

\section{Conclusion}

Deliberate self harm is more common in the younger population in age range of 16-29 years with a global trend of yearly increment in the rate in same age group. Depression is a common psychiatric morbidity, followed by adjustment disorder. Previous suicide attempt and family history of suicide/attempted suicide is seen in some patients. The maximum number of patients chose self poisoning as the mode of attempted suicide, followed by hanging. Organophosphate is a common poison used for self harm. Social and financial reasons for interpersonal conflict and poverty are underlying reasons for DSH which needs to be further explored.

The study has provided preliminary evidence to further explore on the DSH as a social problem. Community based study of similar kind to explore further into DSH at community level can be done followed by further studies to identify community based interventions to address the problems of DSH.

\section{References}

1. Cavenagh JTO, Masterton G. Suicide and deliberate self harm: In companion to Psychiatric studies, $6^{\text {th }}$ edition 1998; 765-772.

2. Yip PSF, Kris Yang KCT. Deliberate selfHarm in Hong Kong SAR (1997-2003). The Hongkong Jocky Club Center for suicide research and prevention. The University of Hongkong June 2004.

3. Subba SH, Binu VS, Menezes RG, Kanchan T, Arun M, Patil R, Pant S, Saha A, De A, Rana MS. Pattern and trend of Deliberate self-harm in western Nepal. Journal of Forensic Sciences. 2009; 54(3): 704-707. 
4. Greydanus DE, Shek D. Deliberate selfharm and suicide in adolescents. Keio Journal of Medicine. 2009; 58(3): 144151.

5. Suicide Prevention in Different Culture 2009. Geneva:World Health Organisation; 2009.

6. Colman I, Yiannakoulias N, Schopflocher D, Svenson LW, Rosychuk RJ, Rowe $\mathrm{BH}$; ED Atlas Group. Population-based study of medically treated self-inflicted injuries. Canadian Journal of Emergency Medical Care 2004; 6(5): 313-20.

7. Owens D, Horrocks J, House A. Fatal and non-fatal repetition of self-harm: Systematic Review. The British Journal of Psychiatry 2002; 181: 193-9.

8. The World Health Report 2009—shaping the future. Geneva: World Health Organization; 2009.

9. Preventing suicide: a resource for general physicians WHOMNHMBD/00.1.http://www.who.int /mental_health/median/en/56.pdf.(Asces s on 2009 Nov10)

10. SUPRE-WHO sites / Mental health / Suicide prevention and special programmes. Prevention of suicidal behaviours: a task for all. http://www.who.int/mental_health/preven tion/ suicide/information/en/index.html. (Ascess on 2009 Nov10).
11. Shakya DR, Shyangwa PM, Shakya R. Psychiatric Emergency in a Tertiary Care Hospital. J Nepal Medical Assoc. 2008; 47(169): 28-33.

12. Conwell $\mathrm{Y}$, Henderson RE. The Neuropsychiatry of Suicide. In: Schiffer RB, Rao SM, Fogel BS, editors. The Neuropsychiatry of Suicide. Lippincott Williams \& Wilkins; 2003, p. 679-722.

13. Shakya $\mathrm{YL}$, Acharya $\mathrm{R}$, Gupta MP, Banjara MR, Prasad PN. Factors determining self-harm. Journal of Institute of Medicine. December 2010; 32(3): 4-17.

14. Beautrais AL. Risk Factors for Suicide and attempted suicide among young people. Australian and New Zealand Journal of Psychiatry. 2000; 34(3): 420434

15. Shakya DR, Pandey AK, Shyangwa PM et al. 'Psychiatric Morbidity Profiles of referred Psychiatry OPD Patients in a General hospital' Indian Medical Journal. 2009; 103 (12); 407-411

16. Cantor C, Neulinger K. The epidemiology of suicide and attempted suicide among young Australians. Australian and New Zealand Journal of Psychiatry. 2000; 34(3): 370-87.

17. Roy A. Suicide. In: Sadock BJ, Sadock VJ, editors. Kaplan and sadock's comprehensive Textbook of Psychiatry, 
Vol 2, $7^{\text {th }}$ edition. Lippincott Williams and Wilkins; 2000, 29.1:p.2031-2040.

18. Vajda J, Steinbeck K. 'Factors associated with repeat suicide attempts among adolescents' In Australian and New Zealand Journal of Psychiatry (2000; 34(3): 437-445

19. Pradhan SN, Rajbhandari KC, Sharma VD, Khalid A, Koirala NR, Ojha SP, Pokharel A, Sharma SC, Rana M. A study of mode of attempted suicide. 2001 ; 2(4): 100-107.
20. Mann JJ, Arango V. Neurobiology of suicidal behavior. In The Harvard Medical school guide to suicide assessment and intervention, San Francisco, California, 1998:98-114.

21. Shakya DR, Shyangwa PM, Sen B. Psychiatric co morbidity in cases admitted for Alcohol dependence. Delhi Journal of Psychiatry. 2009; 12(2): 252257. 